\title{
浮选理論的現狀及进一步研究的方向”
}

\author{
胡为柏 \\ (中南矿冶学院选矿系)
}

浮游选矿法可以境是二十世紀科学技术的出色成就之一。近代的工業浮选是1860年 左存开始的，但是基正的擼拌起泡的泡沫浮选法在 1914 年左右才出現。在这不到 50 年

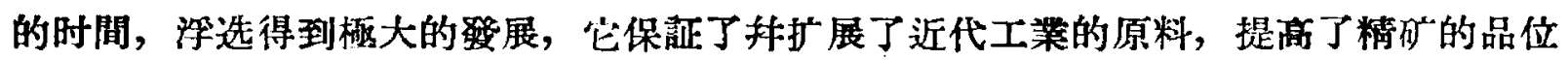
和采收率，使資源的綜合利用达到相当高的水本。我国在解放以后，浮选工莱才得到很 大的發展。我們目前已有了銅、鉛、鍄、鵭、鉬、䖝石等的浮选厂，有了浮选剂制造厂， 浮选机械設备的制造厂以及选研“研究机棈。今后浮选工業將得到更大的發展。最近党又 提出了十二年內接近世界先进科学水平的号召。在这号石的鼓舞下，各門科学都需要了 解情况, 找出方向, 井作出䙺划。本交就是尝詿介紹浮选理論的几个問題的情况, 投堤 出些进一步研究的方向。所介紹的是最近五年間苏联及美国、德国等發表的主要研究成 果。內容是不够全面的。希望請者討論指正。

\section{一 矿物內部結楼及表面結構与浖选的关系}

矿物可深性的差別是浮选的基础，这与矿物䊅㭊有什么关系? 是浮选理論的基本問 題。

固体結晶晶格的排列和分子間力的研究，是解释昒物潤湿性（䟲水性、亲水性，䟽 油性、亲油性等) 的理論根据。

苏联学者斯特列㴖 (Г. С. Стьрельцын) 經过研究了一系列矿物的晶格之后, 他指出: 有許多矿物（如石墨、輝鉏矿、硫等）, 其晶格內部是屬于原子（共价）結棈, 而有一定 的結晶面是屬于分子（凡德瓦尔氐）結構，当其断裂面是沿着較弱的分子結合面时（这 是一般的情形)，則矿物表面是䟽水的; 当裂面是强的原子結合处时 (这是特殊情形)，則 表面是亲水的。他篔根据矿物表面的結合力作出分类表。認为矿物表面主密为分子粘合 或原子䊅合，前者因其作用力弱故为疏水的，后者为亲水的。

当然, 如果我們能从矿物的內部粘楎（这是用 X 光能解 决的）来推断解离面, 然 后推算解表面分子与水上至与葯剂之間的相互作用力, 那末我們將会推测到許多浮选 的基本規律, 換言之, 我們就有可能利用 $\mathrm{X}$ 光結楎分析这一因素, 来預見科进一步控 制浮选过程。但是目前在这方面还存在許多复杂的問題。

綜合目前結晶化学的成就, 在这方面可提出下列儿点:

- 本交采由作者在今年 6 月15日“深选科学討論会”上所作的报告删落而成。

11 月是科学通报 
1. 內部是离子結棈的的物（如䖝石），其表面是离子結合，表面的作用力場是滀子静 电力場。

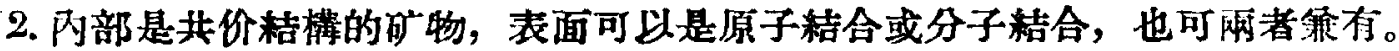

3. 如果表面作用的是离子静电力場，則此表面对于極性的水是很易起作用的，所以 是亲水的。如果表酘是原子結合 (如金銅石、線柱石、石英等)，有較强的化学杽的作用， 所以她是亲水的。对于这类旷物，需要用复够性分子結構的捕集剂。

4. 如果表面是分子桔合，其作用力場是凡德瓦尔氏力，这就要再进一步加以分析。 如榡其組成力主要是轉动效应和誘起效应，那么此表面还是極性的，科且是亲水的（当 然在亲水的程度_上不及离子結合那么强)，对于这类的物也需要复極性的捕集剂。如果其

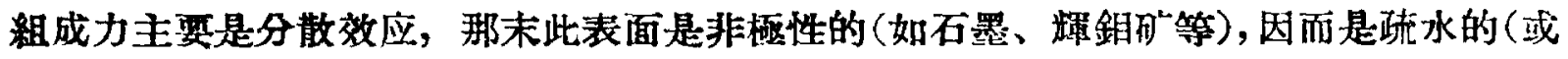
請对对水的作用力很弱)，对于这类旷物可用非極性的捐集剂。

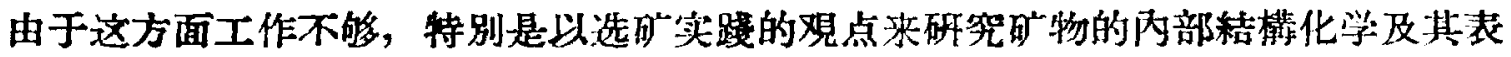
面性照間的关系的工作做得不够，所以还不能肯定地用結棈分析的方法来控制沙选过程。 种且，在进行这方面研究时，出現了許多复杂的情况如：

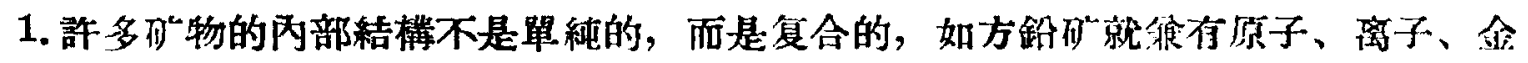

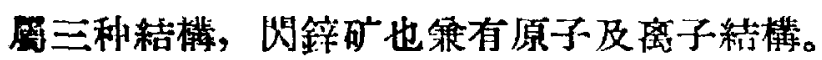

2. 內部結構常是各向异性的，即沿某些結晶軸或䊅晶面方向的性筫与号一方向的性

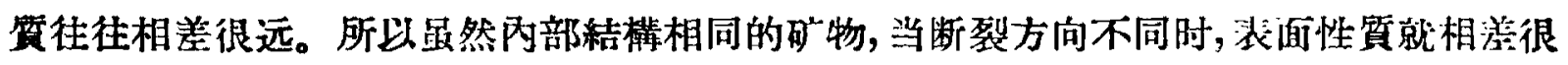
远，甚至同一矿物因解离方问不同所表現的性質也不同。

3. 䊅晶昆格的不連結性和表面的不均匀性, 对于矿物的海选性質往往起很大的影吤。

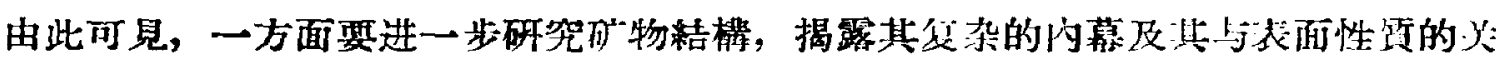
系。但是另一方面，还必須深入研究昆格的不連續性和表面的不均匀性。

对于浮选有很大关系的, 首先是“倓唋結構”。这是由于我們平常所遇及的破物，几 乎完全没有是由完善的單晶組成的。而是由無数的微晶組成的。当这些微晶互相谈鑲組

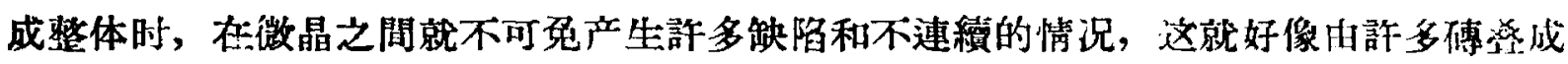

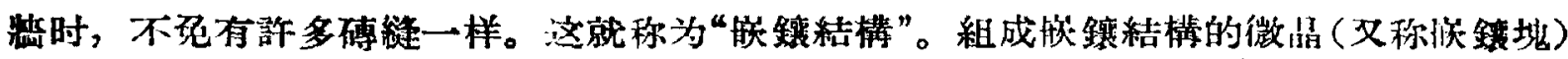
的大小和取向，因䊅晶的生成情况和維所而不同，其大小仃以从 $50 \AA$ 至 $50,000 \AA$ ，而呈 各种規則的或不規則的取向。

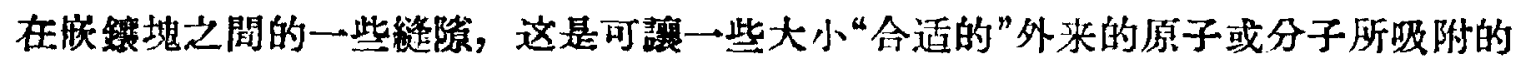
“㐫表面”，比起一般所認为的固体的“外表面”要大得多。

称过唝附方面的研究，知道有些化学成分完全相同的固体洏有很不问的吸附性筫，

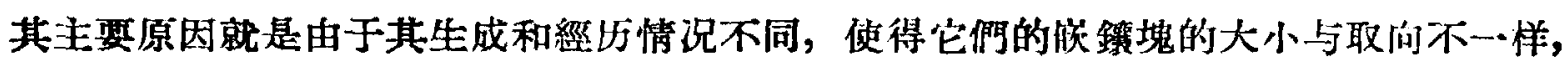
于是縫吵（即內表面）也不一样，所以对于外来分子的吸附性犋也不一样。

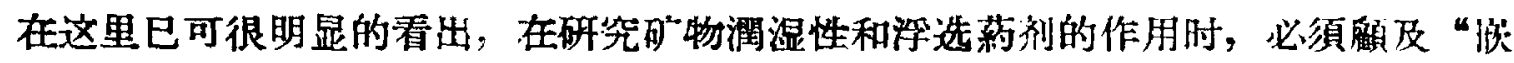
銥結棈"。

譬如说，目前用同位秦的研究証明：捕集剂的吸附量与采收率常常不能成䜣比的X 系，有的指集测的吸附量只足以唯盖 1\%-5\%表面，也就能海选，吸附薄膜的流动性和

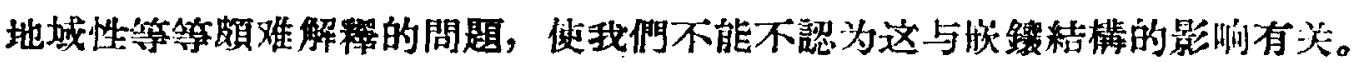




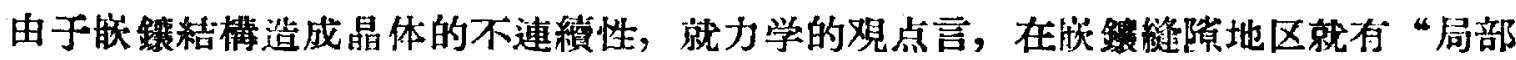
应变” 乍在。根据理論的計算，一个离子結晶的內应力比我們实际測得的要大十倍以至百 倍。为什么我們可以用比理論算出所需的少得多的能就可把矿物破碎呢? 主姴原因可能

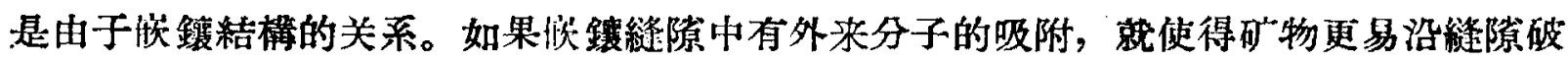

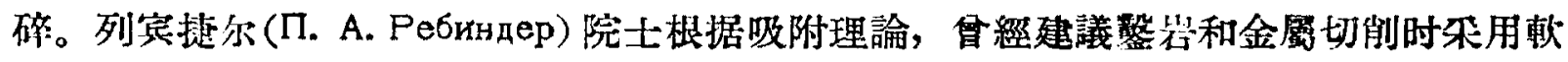
化剂，在工業上起了很大的貢献。后来齐略金 (Дерягин) 又从理論上加以浬明。在这里 我們可以有相当理論根据提出，如果进一步研究处理矿物的方法，使矿物的闻较塊的大

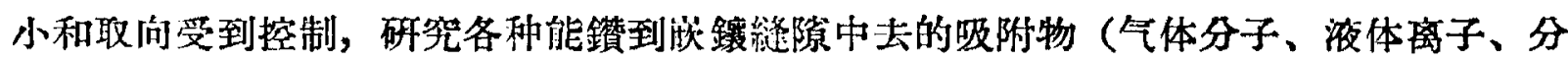
子以至固体分子等）的作用，当可大大提语䄷矿效率，科且既然“局部应变”和 “不本衡

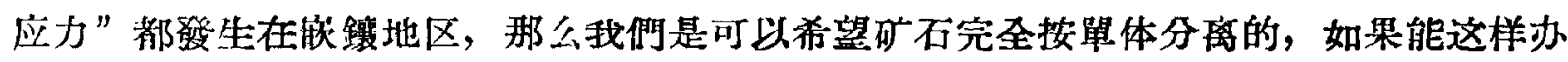
到，那选矿就来得容易得多。問題是如何使外加应力能恰当地作用于浣踝地区，对于目 前所用的鉏击磨研等破碎方式显然是不侈好的。必須开辟新的破碎方法，暨如境高頻本 振薄，超音速振漟，頻萃很消的加压减压反复处理等方法，是值得考虑的。

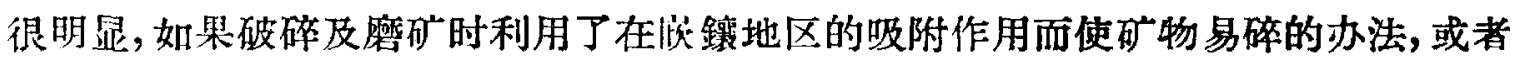
用新的破碎办法使矿石完全呈單体分摛，那我們浮选者所面对的矿物表面性僙也出現了 新的情况。

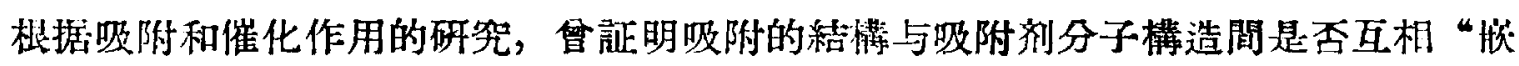
合”，对于吸附和催化作用起很大的影响，所以对浮选剂分子或紊子与矿物婊面結棈是否 互相“垁合”的研究，将会得出許多有益的結果。

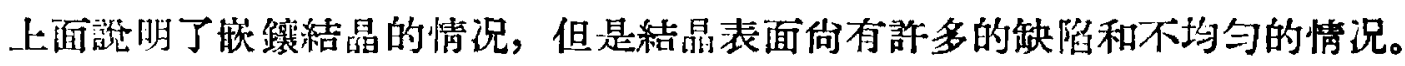

（1）杂賢的影响：如目前在牛导体中，知道十万分之一或百万方一的 $\mathrm{Sb}$ 对 $\mathrm{Si}$ 就 起很大的作用。苏联科学院曾研究了各科矿床的閃鋅矿，証明虽然同是閃鋅矿，但浮选 性質很不一样，这与該矿物中的鎘、鉄等的杂質合量是有关系的。目前对于各种矿物中 極徽量杂筫与浮选性翼关系的研究还很不够。

（2）原子的錯位（或称脫节）而造成的晶体缺陷，关于原子的錯位与与铁陷，目前 在金屬物理学的領域中巳进行大量的研究，这些研究对于固体性筫的了解和浮选基本机 構的了解，将会迪一定的作用。

由于結晶的不連續和缺埳，这就在棈造上造成表面的不均打性，加以固体中的分子 不如液体和气体分子那么易于流动，所以在表面各点的能位常常处于極不均衡的狀态。 在吸附研究中証明了固体表面各点的吸附热是不一样的。譬如在氯化釬转照表面上以氩 吸附时，証明恰恰在 $\mathrm{K}^{+}$离子表面的力場与介于 $\mathrm{K}^{+}$度 $\mathrm{Cl}^{-}$之間地区的力場是不一样 的。这就說明了矿物表面对于浮选剂作用的力場也各点不同的。在催化作用中，有“活 性中心”的学浬, 但这学證还没有在浮选領域中發展起来。同付, 由于表面的不均匀性, 固体表面的吸附膜也就处于位能不斥衡的狀态，根据热力学第二定律，吸附膜有从槀能 位移动到低位能的趋势。伏尔母尔(M. Volmer) 等管做了許多实验証明表面吸附膜是会 “移动”的。从能的覌点来看，如果吸附分子的平均动能超过了陆制它运动的能峰 $\Delta \mathrm{E}$, 移 动完全是可能的。月前認为对于物理吸附的分子膜，由于它的 $\Delta \mathrm{E}$ 相当小，在室温时也 可能移动。对于化学吸附的分子，由于它的能峰 $\Delta \mathrm{E}$ 大得多，移动就比較困难，除非在 


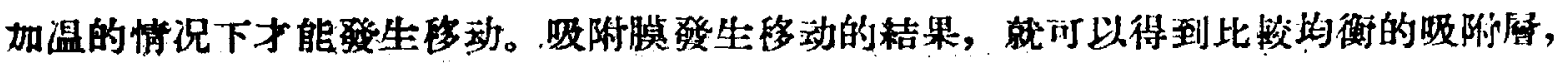
从而在某些情况下对浮选有利。深选䖝石和闪菱矿等需要加温的事实, 可能是由于促进 吸附層的运动的緣故。

关于䊀昆的不連續和表面的不比匀性，目前主要的研究方法是吸附。

矿物內部結棈及其表面結棈对于海选的沃系，是浮选理論的基本問題之一。

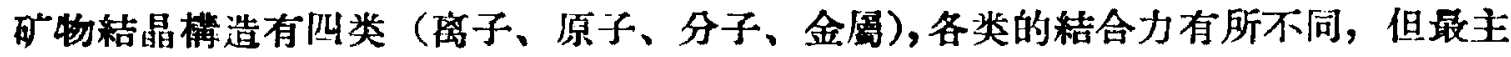
要的是分子間力（凡德瓦尔氏）。这科力是由于相鄰分子內的电子間相互作用引起的：即 （1）辒动效应，(2) 誘起效应和、（3）分散效应所引起的。

从矿物內部桔棈, 有时可推断最可能的解离面, 从解离表面的力場, 可推溉研物的 䟽水性亲水性以及可能应用的捕集剂。但是由于許多复杂情况的存在，目前还不能用矿 物結粠分析这一因素来挖制浮选过程。

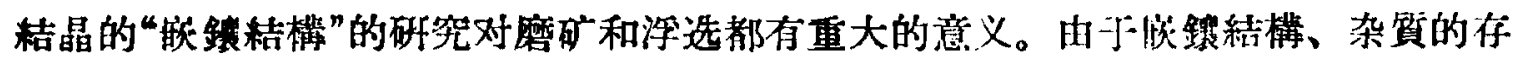
在和粘晶的缺陷等，造成表面的不均匀性，这方面的研究已經使我們可以認定研“物表面 的吸附是有“活性中心”的，持且这吸附薄膜还是会“移动”的。

从上迅简單叙迅中，可提出下列的研究方向：

1. 䜌續研究矿物的內部結晶及其解离面的規律, 找出解离出来的的物表面的力場及 其种种浮选性咓。

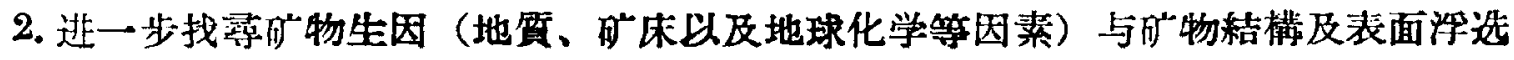
性質的关系。

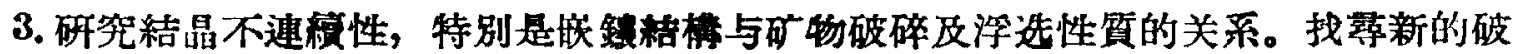
碎方法，得到新的而可控制的表面。

4. 研觉矿物表面的不均匀性，找出控制表面不均匀性的方法（目前在金算学中，表 面处理和热处理的方法已清度發展，而用表面处理的和热处理等方法来控制矿物表面的 浮选性質也是有發展前涂的)。

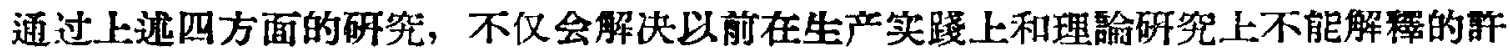
多問題，还会發展成立 “浮选結構化学”、“浮选破物学”等新的学科。科且还会發展成 “矿物表面处理”等新技艺。从而將浮选向前大大的推进。

\section{二 矿粒固着于气泡的机理}

矿粒如何固着于气泡而上浮的? 是浮选理論的第 2 个基本問題。

对于这一問題的了解，測量在各种不同条件下的选擇潤湿作用所引起的接触角和阻 灌現象, 是有重要意义的。虽然接触角測量方法上还有許多缺点, 抹且有个別研究工作 者表示反对，但对于旷獎中的的物表面受化学或吸附过程作用所起的变化，亦即是对于 矿物表面可浮珄的好坏的判断，还是栖有价值的。

矿粒和气泡接触形成一个复合体的时候, 介于气泡与固体接触面之間有殘余的水化 灌膜，所以就生固相与气相究竟是否接触的問題。潤湿接触角理論是認为接触时水化 膜是破裂的，即認为形成“三相接触。”根据潤湿接触角的假䚺，砋粒向气泡固着过程之 
所以能自發进行，其根据是热力学第二定律，即由于固著后系統的自由能比周羊前低， 固着过程中表面自由能 $(\Delta F)$ 的减低。

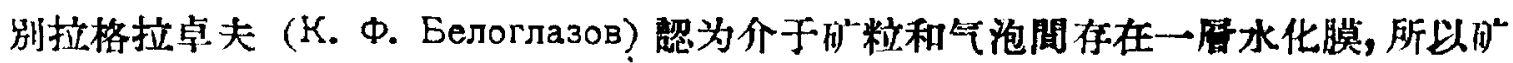

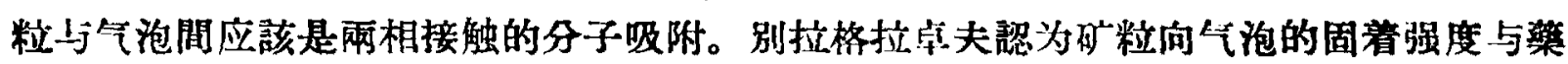
剂的毛綝常数和吸附常数有关系。抹且得出一个令人注意的方程式，但是該式是在許多 假定下导出的，他認为固着强度仅与捕集剂吸附厤的湮度有关。这是不的精确的，因为 許多实驗都証明其他深选剂（起泡剂、調整剂等）都会对固着强度發生很大的晾响。

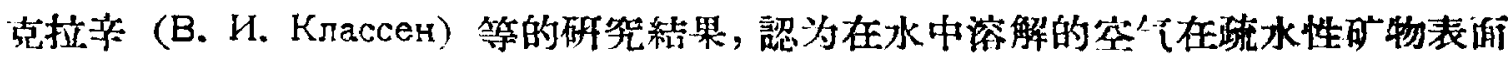
是微泡析出，此項徽泡再与”泡“策科”，是仢粒向气泡固着的机理。他合部明，由于微

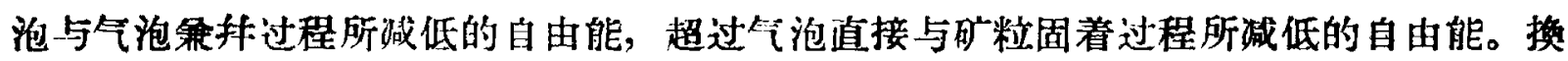

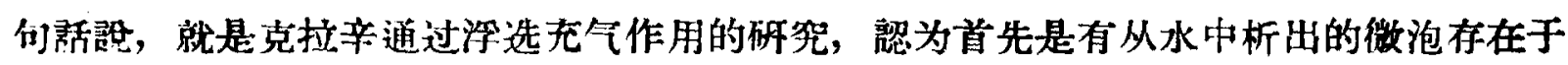
可“粒䟽水性表面，然后微泡与气泡策抹而造成浮选基本行为。

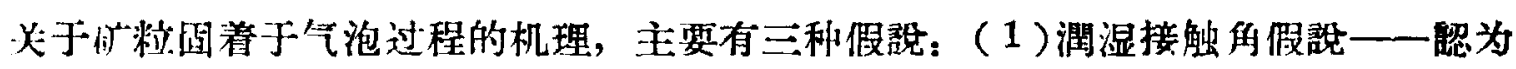

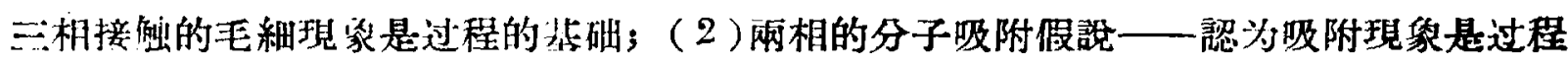
的基础; (3) 微泡的作用假弪——認为微泡的析出和策升是过程的基矵。

到目前为止，还不能肯定那一种假䛸完全对或完全錯。

找們認为，由于浮选过程基本㺕生于相界面，从相界面的自由能的覌点来研究浮选 过程，也就是䛸，研究潤湿理論是正确的道路，虽然目前用接你角的方法来研究潤湿理 論布許多缺点——特別是缺乏精确的数量关系, 但是还不失为一个重要的方法, 問題是 如何非一步加以發段。

关于分子吸附假䛢，当然，在矿粒与气泡間有捕集剂的吸附是可以肯定的，而固着 强度与吸附贋濃度有一定的关系也是岌定的。別拉格拉卓夫在这方面开創了新的道路。 但到目前为止，別拉格拉字夫的机理和公式却有一些不足之处一一譬如不顧及起泡剂調 整剂的作用（最近修曼(J.H. Shulman）等的研究証明起泡剂与捕集剂之間起一定的作

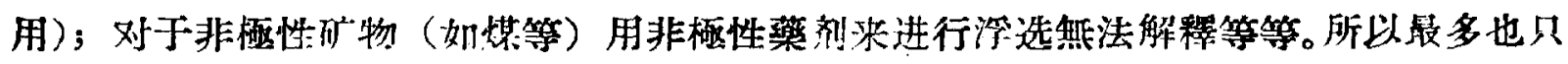

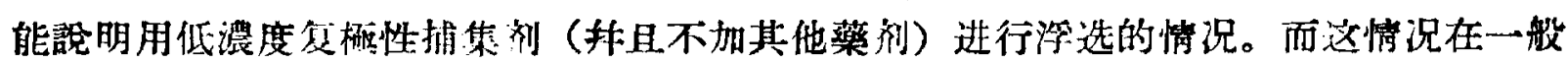
浮选中是等有的特殊情况。

年于微泡的作用，正如大多数学者所公琶的，就是微泡对于浮选有一定的作用，但 决不是起主导的作用。

关于两相接触和三相接触的爭綸，問題中心是固体表面水化膜能否全部破裂？根据

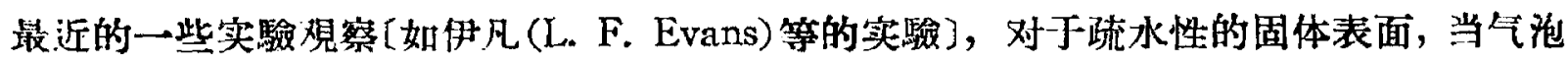
逝近时，部分地区的水化膜是会破裂的。所以三相接触是可能的。总的来鿁，炎于矿粒 如何与气泡固着的研究，大体还停留在静的性翼的分析，缺之动的数量的分析，这就使 得研究条件与浮选实际情况有些脱节，今后必須克服这利脱节現象，才能使理論向前推 进, 所以今后的研究方们将是:

1. 糍續研究接触任数值和气泡大小对矿粒向气泡固着力的影响; 矽究浮选过程中接 触角的变化; 研究樂剂对接触角和固着速度的影响。 
2. 研究在近于浫选的条件下, 即在有各种浮洗剂存在的条件下, 固液界面的水化现 象; 研究水化膜的性留及水化膜变薄以至局部或全部破裂的动力学。

\section{三浮选利的作用}

关于浮选刘作用的研究，近年来在苏联及其他国家都进行过大最的研究，利且今后 还是浮选理諭研究的重要方向之一。

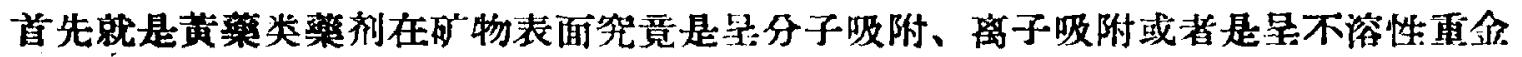
局黄酸監直接粘着的問題。

苏联机械选矿研究所的一些学者，㗏明重金屬黄酸監的微分散沉淀，汀能把硫化矿” 㐿起。苏联科学院矿業研究所的实驗証明, 用不溶性黄酸監来浮选是可能们, 但必須有 氧存在, 否則無效。而具升不是直接粘着, 是在与氯存在时张生化学吸附的結果, 其吸 附可能是分子吸附或离子吸附。柏拉克辛 (К. Н. Плаксин) 院士在 1948 年根据或的作 用形成复層的研究和非离子化合物 (复黄酸) 的作用䂺究結果, 提出了这样的假珫: 就 是黄酸監在硫化的表面初步吸附是分子狀态然后变为黄酸离子，由于离子交換呈坚洞组 着情况。最近柯克 (M. A. Cook) 等的工作認为可能是白由黄陵分子(星活性綜合物啲 阶段）的吸附。而米特罗方諾夫（С. К. Митрофанов)也有分子吸附的想法。

关于捕集剂固着首的情况。安非莫姓 (E. A.Aнфимова) 等的研觉証。明，浮选所需捕 集剂固暑罩盖程度，与活化作用有关，拆且因所用的藥剂而不同。

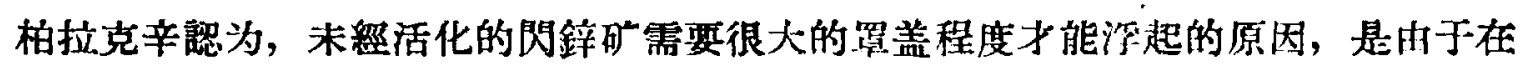

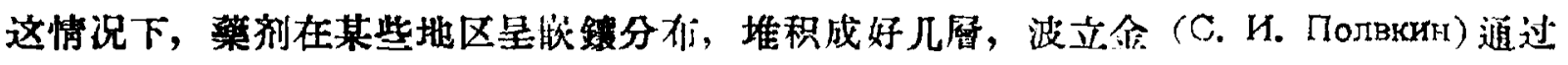

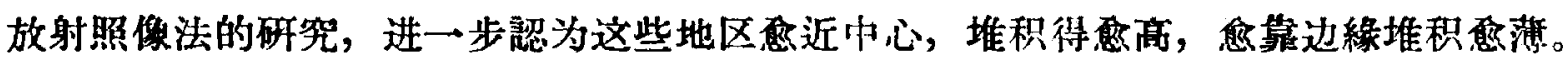

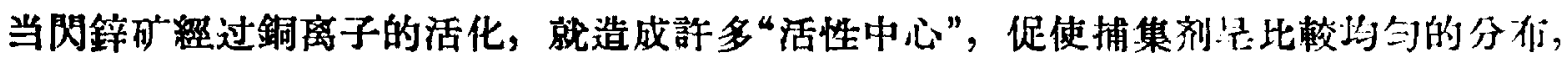
从而利于浮选。

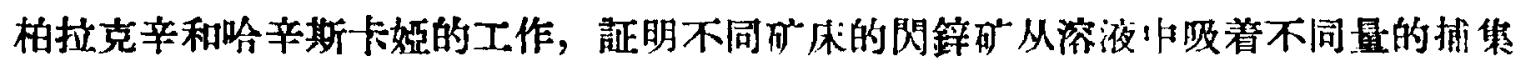
籼。

从这一研究工作及其他研究工作，都使人認为，矿物表面罩垍的形成条作，对于深 选起很大的影响。

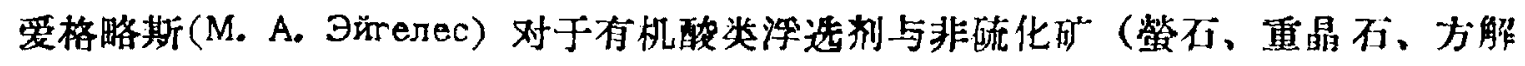
石等）的作用筸作了極其阔咩的研究。他認为油酸鈵对非硫化矿作用，同时进行着“川 逆吸附”和“不可逆吸附”的过程，前一过程进行很快，形成多分子居的吸附，这和吸附 是不隐定的，因而可被水所解吸; 后一过程进行很僈，形成不超过筆分子的隐定的吸附 居。但是他的許多实驗数值，还不足以完全引出这一桔論。

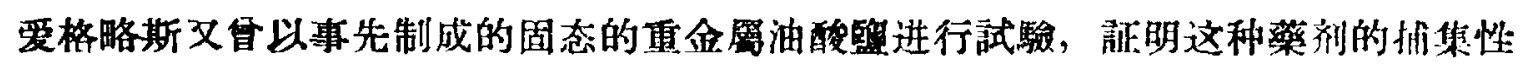
委一些。

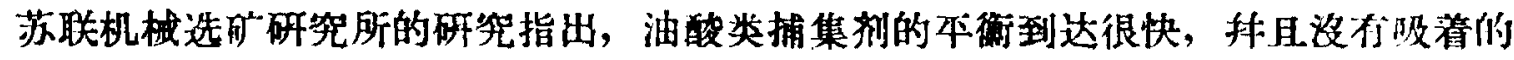
可逆性。在表面形成的化合物强固地固着在的物表面。他假也用新鮮的脂肪酸伤留沉注 制成的微分散体中来浮选溃石，証明它的捕其作用抹不羔。他們还合研究了在不间的 $\mathrm{PH}$ 条件下，油酸解离度的变化，証明了由于水解作用和它化作用，在旷獎中同时有油酸 


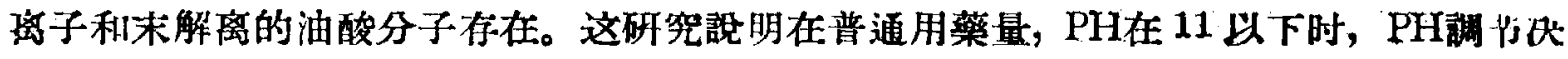
定了矿漿中油酸的离子䍚度。

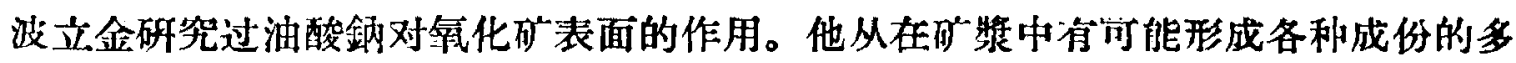

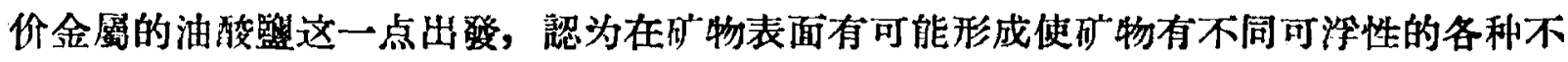

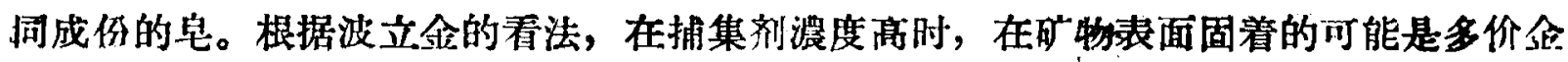
屬油酸監的皇的膠胞。

苏联机械选们“研究所的登尼洛夫 (E. В. Данилов) 每作过十二胶对非硫化矿作用似 研究。由計算的結果得知, 十二咹在 $\mathrm{PH}<9$ 和酸性介質中, 呈离子狀态, 而在 $\mathrm{PH} ，-9$ 的睮性介筫中，胺呈分子狀态。

在用十二咹来浮石英和長石的結果詰明，起作用的是陽离子 $\mathrm{RNH}_{3}$ 。把石英精矿进

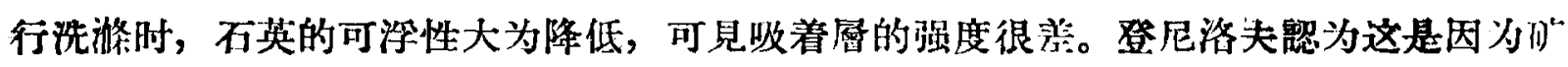
物与㤞的交換吸附，即 $\mathrm{RNH}_{3}$ 与位于扩散臂的 $\mathrm{H}^{+}$离子交換。在浮选長石胕，加入 $\mathrm{HF}$ 唆 订增加長石的可浮性, 登尼治夫認为这可能是时于HF 与十二胶在溶液中互相起了作用, 生成对長石有特殊性䁈的新化合物的䋎故。

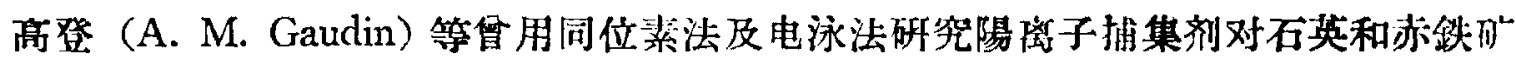
的作用, 証明在们“物表面的捕集剂与溶液中的捕集剂起交換作用。而且部明当石英表面

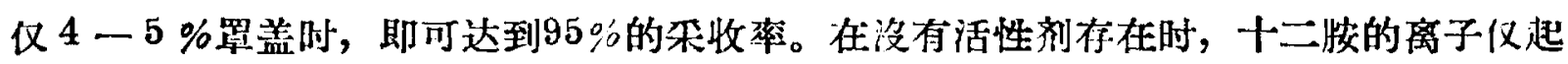
压縮双电層的作用; 在有活性剂存在时，十二咹离子与呈化学吸附的活性离子（如鎮离 子）在双电鹭队結合。

現厂实际工作的經驗訕明，將好几利捕集剂混合使用比單独用一种捕集剂，棌选絬 果好得多.

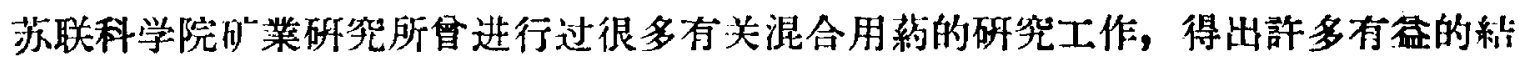
果。

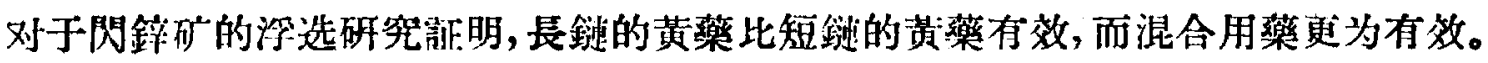

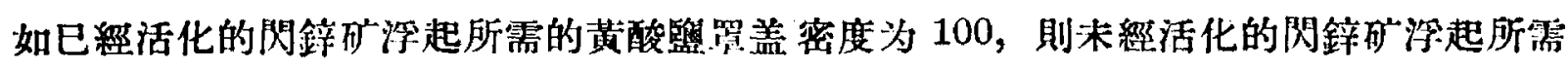

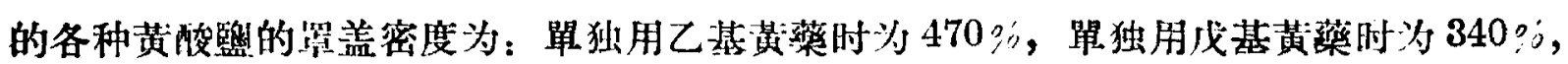
混合使用时仅为 $275 \%$ 。

混合用䒚的效果在銅鋅矿的現厂实驗中也得到証实，在用网种鱼䒚时，比單独用丁 基黄藥时，使銅在尾矿中的損失减少 $4 \%$ ，鋅的損失减少 $1.5 \%$ 。

在單独使用时本来没有什么用的甲基革䒚，但是与其他黄䒚混用时，却成为很有效 的成分之一，这可能是由于混合使用际，藥剂間發生的相互作用造成新的捕集性貿。

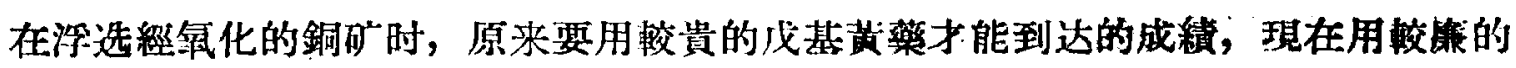
黄樂（丁基、异丙基）混用可得到相同的成精。

苏联科学院矿業研究所骨研究了各种黃藥混用, 黄藥与黑樂混用, 非極性的和复椅 性的捕集剂湿用, 部明在适当的混用条件下, 可以促进浮选速度，从而使浮选过程强化， 还可以减少用量, 这就可娍輕徽粒的絮凝, 从而改善分选指标。

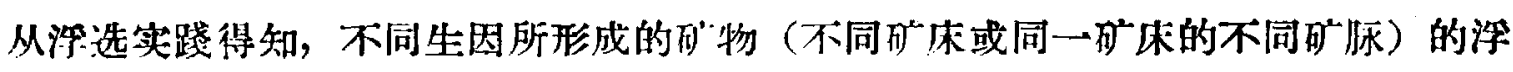
洗性賀会不一样。格列姆波次基（В. А. Глембоцкии）筜研究了苏联某儿个矿床的方錐 


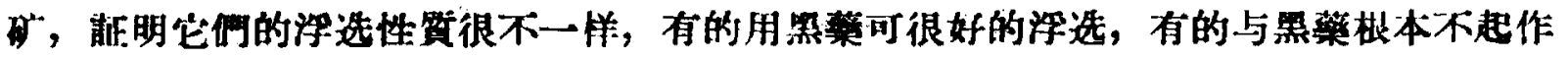

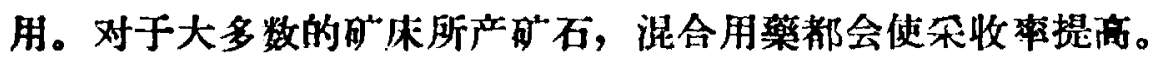

关于混合用樂的研觉，最近几年来虽出現了很多論文，但对于这方面的規律和作用 机理，还没有很好的解决。目前对于为什么混合用藥比翌独用藥存效的問題，認为与 (1) 酐物表面的不均匀性，（2）石物的不同氧化程度，（3）調整剂等的作用有关。但其詳

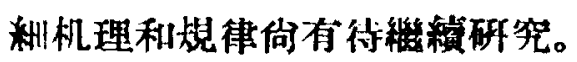

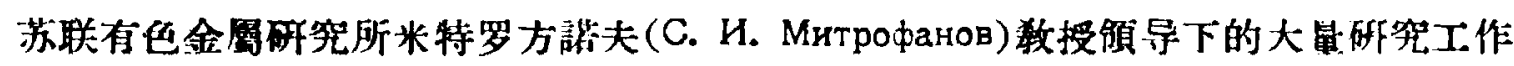

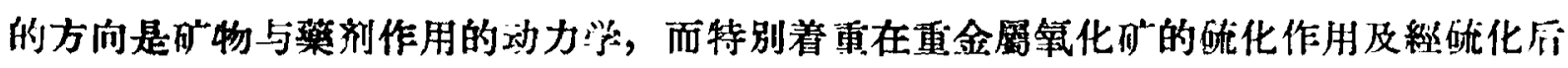
的捕集剂作用。他們用同位素示踪原子的方法研究了白鉊和和的孔雀石的表面硫化作用，

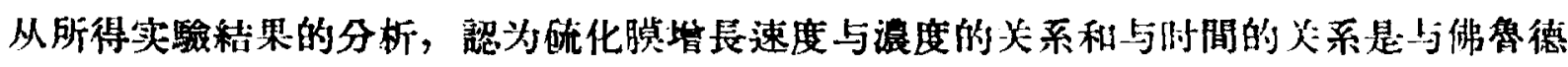
星! 区的吸附式相似的。这一研究对理諭及对实蹬都有很大的意义的，但需要从純研“物的 研究进一步研究湜合的物以至天然的石。

关于诵化物的抑制作用，卡科夫斯基（И. А. Каковский）等的工作是特別值得注意

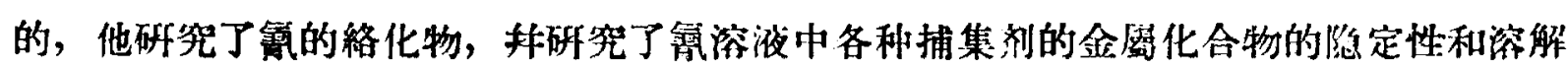

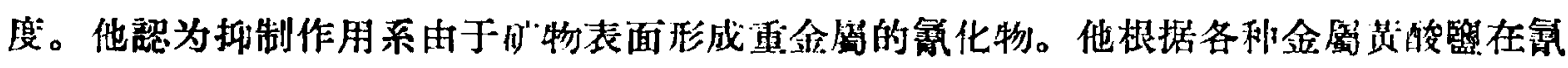

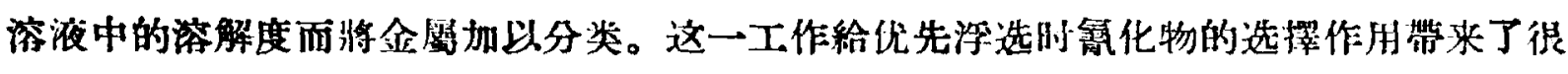

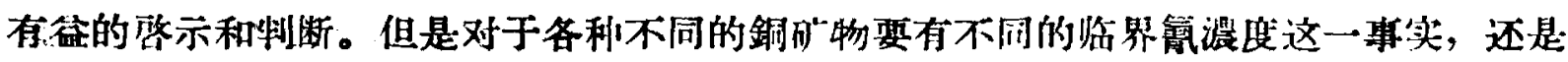
不能鿁明。

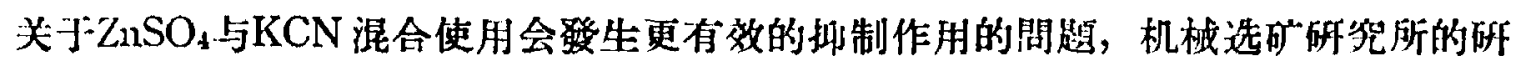

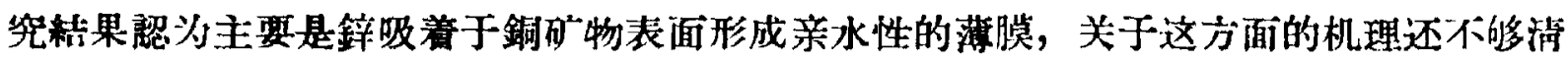
楚。

馬林諾夫斯基 (В. А. Малиновский) 等研究 $\mathrm{ZnSO}_{4}$ 的抑制作用, 趾为起作用的是粗 附在的物表面的答体 $\mathrm{Zn}(\mathrm{OH})_{2}$ 。

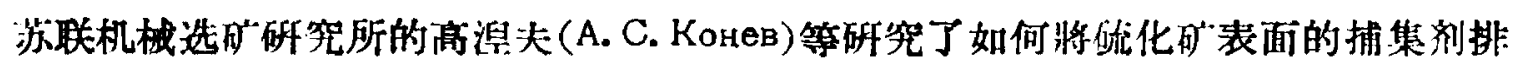
除的問題, 䊀果梕为最有力的是 $\mathrm{Na}_{2} \mathrm{~S}$, 由于这一研究, 使得全浮选 (混合深选) 的流程 能大量的应用。

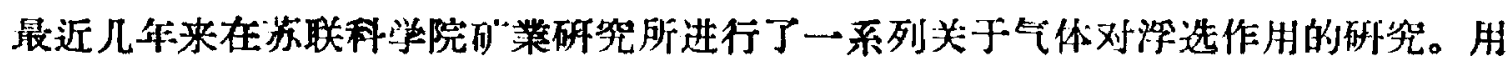

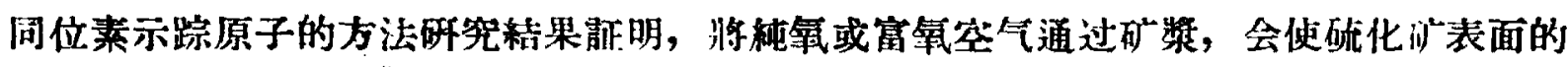

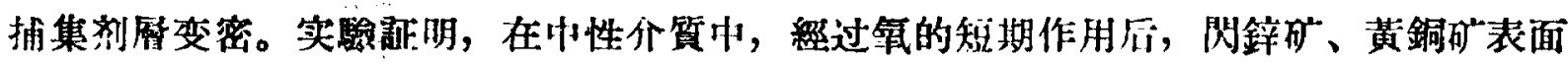

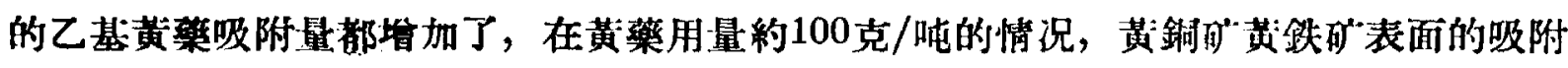

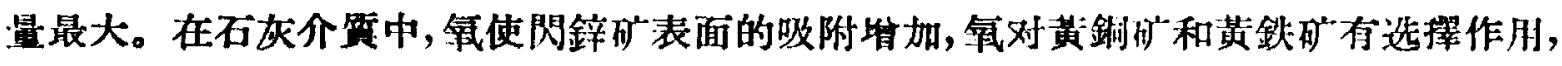

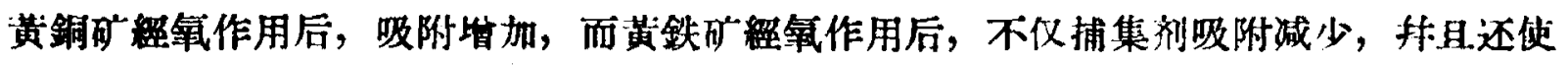
吸附过程变慢。

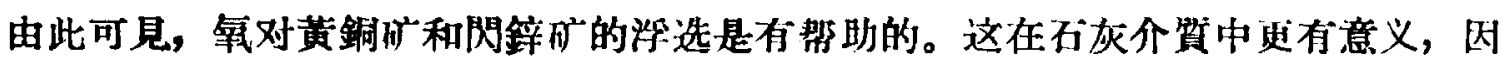
为在石灰作用下，硫化矿对黃樂的吸着是被减低了。从这里已可能得出結論，加昰会隹 捕集剂的吸举增加，对浮选是好的。

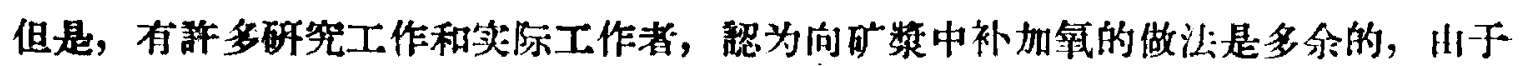

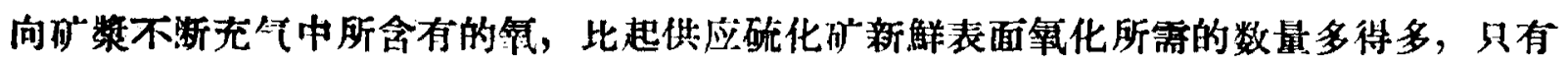


在浮选某些含黃鉄矿”的矿石时；加氧才有意义。

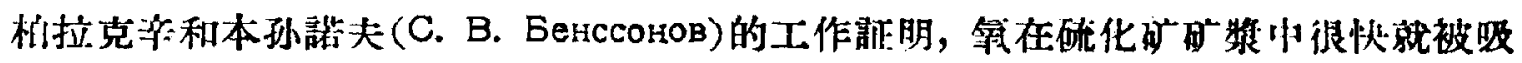
收殆尽了，在畧性介質中，氧被吸收得还要快。

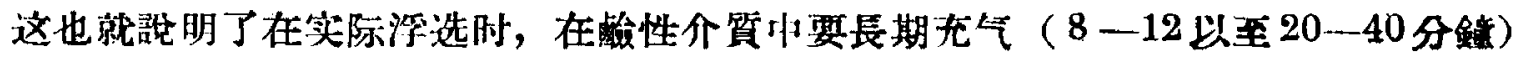
才能把黄鉄矿”、磁硫鉄矿“等抑制下去的道理。在进行黄銅们“和磁硫泆石”的分洗时，磁硫

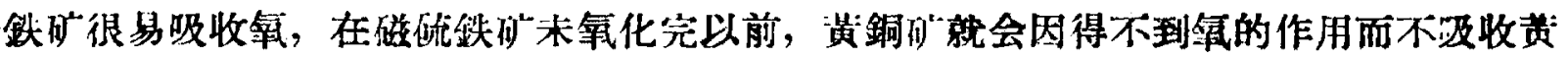

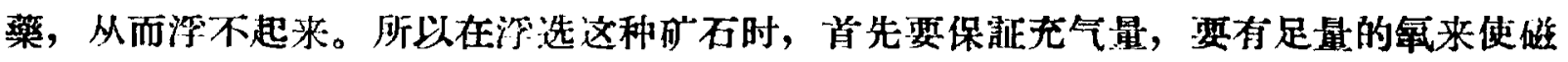

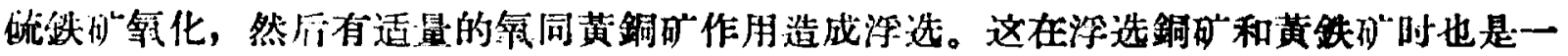
样。

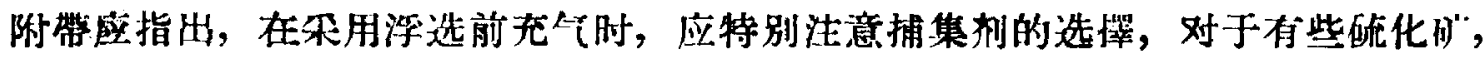

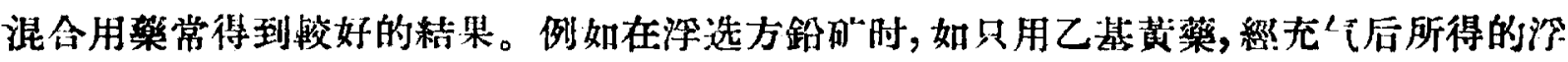

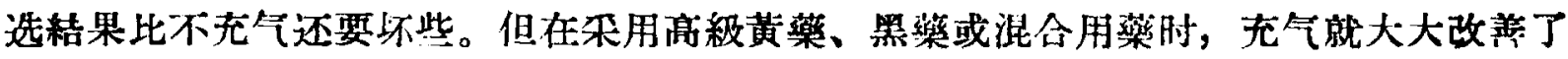

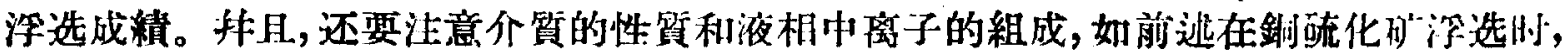

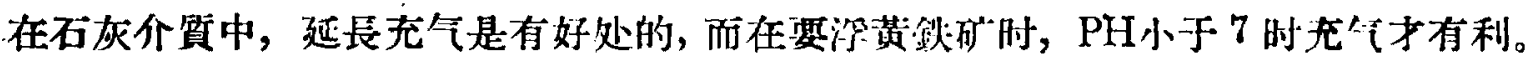

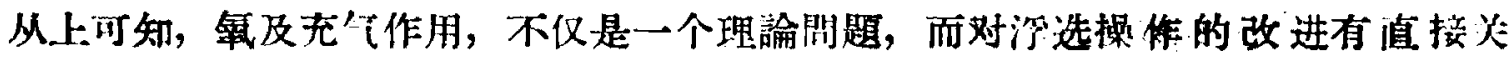
两。

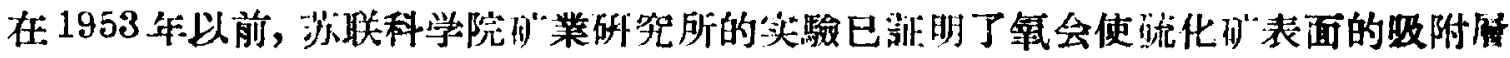

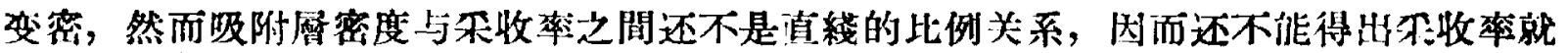

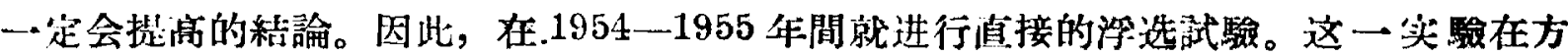

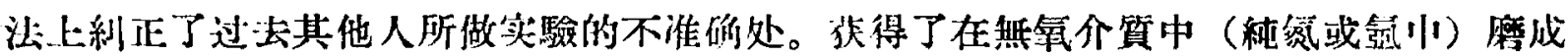

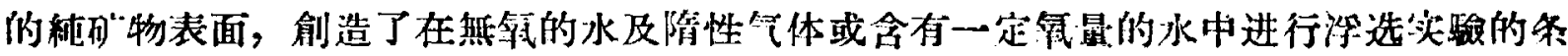
件。根据实㧱待出下列重要的結論：

（1）純硫化矿表面在無氛的水中是亲水的。

（2）捕集剂必須在有氧存在的情况下才能与硫化明“作用，在其他条件相同时，氧

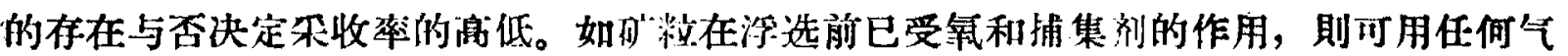
体（犝隋性的純氮地可）作为气泡将它浮:起。

(3) 对于各和不同的硫化矿”，由于“它們对氧的活性不同，需要不同分量的集与它 作用。方鈝矿在含氧很少的水小（含氧 $1-2$ 毫克/升甚至十分之儿克/升）就能海

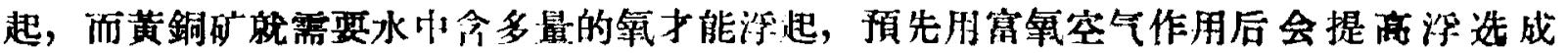
樍。

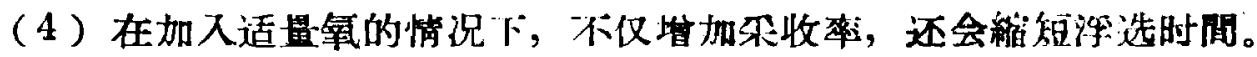

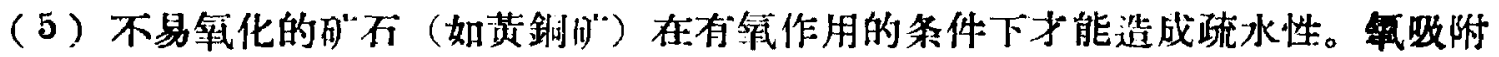
在黄鍴何“表面，在起化学变化之前，这时黃銅们“有了疏水性，甚至不加捕集剂而仅加起 泡剂就能浮起。

如果完全沒有藥剂存在的条件下，气休究竟有多大能力侹硫化旷造成疏水性？从接

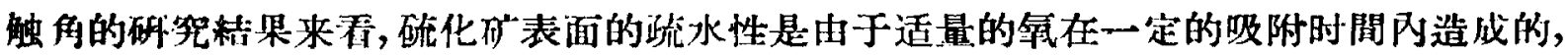
如果用量不当或作用肘閒过長，就会变回亲水性。用更新的研究方法（湘量用”粒向气泡

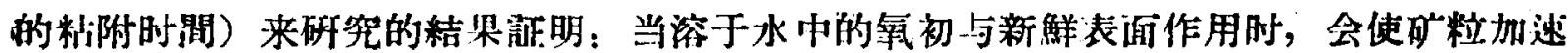
11 月号
科学道报

- 39 . 
间'沲粘附，但如果作用过度，又会使料附变慢基至停止。

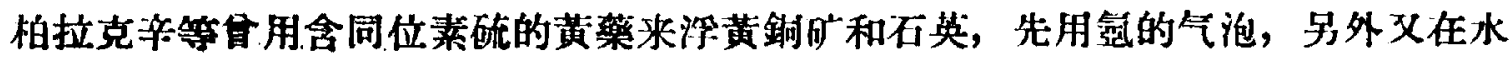
小加入 0.16 至 30-3E 毫克/升氧进行浮选, 然后湘定 黃樂在精矿、星矿和液相中的分 布。实驗耛果证明, 当水中含氧很少时, 即使黃菜用量达 1000 克/吨，不会吸附至旷物

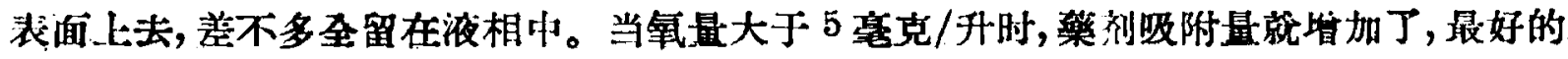
情况（即吸附量及梁收弹都最淌）是氧在水中的搌度为 10 毫克/升，用㩰量为 1000 克/ 吨。这就证明了的物表面的疏水性和䒚剂与氧的作用都有关系。

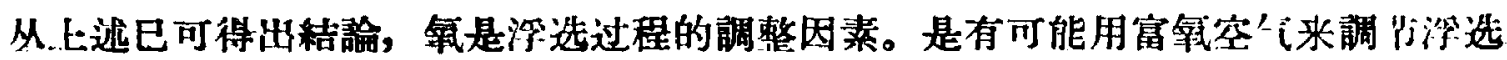
过程的。

氮的作用的理論訆明, 目前也还不的明确。柏拉克辛等認为，氧的分子綵棈们能是

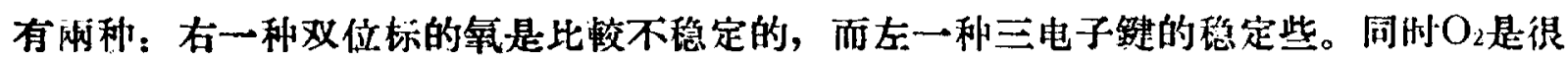
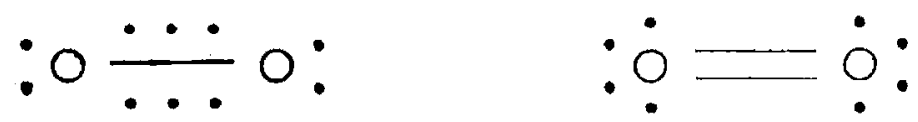

强的原子秥合，而在空气中还可能以较弱的分子結合成O*，而偂吸附到硫化矿表酒使其 疏水的原因，可以設想为 $\mathrm{O}_{4}$ 的分子鍵弱，所以星 $\mathrm{O}_{2}$ 分子附在表面上。根据他們的推淅，

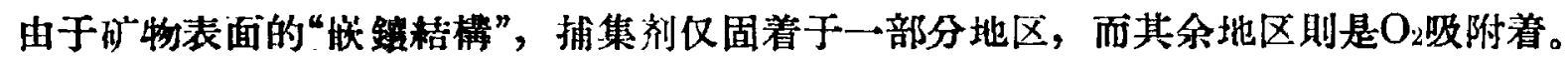
他們还推断，当矿粒向气泡固着时，由于氮的存在，会促使水化胋的破裂; 而捕果测間

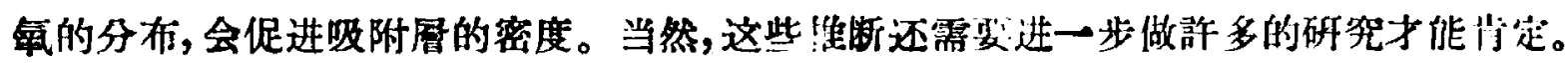

从上迅不完全的介紹，已程足以看出浮选剂的作用是相当复热的，各种藥剂在不同 的具体情况下有不同的作用，必須进行具体的分析。如果想武断地用所謂“吸附学詵”或

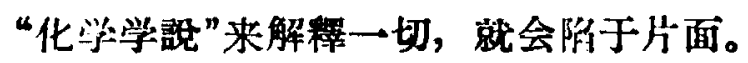

我們研垫浮选剂作用的目的，主要是（1）丁解菜剂作用的䙺律性，(2) 改进实际 操作中的菜方，（3）找寻更便官更有效的浮选剂。到目前为止，我們还远远沙有达到这 个日的。

在浮选剂的作用方面，今后要进行科究的方向是很筧广的。很迫切的方问是:

(1) 研究浮选剂的結傋及其物理化学性質和浮选性質的关系。

(2) 䂰究捕集剂的作用机理，特別是陽离子诚集剂方通。

（3）在最新的呼究方法的基础上, 呼究诚集剂單独使用和混合使用的机理.

(4) 研究国产的油类脂类作为起泡剂, 开辟起泡剂混合使用的新研究方们。

(5) 着重研究調整剂的作用，特別在有机盟体抑制剂方面的修究。开展混肞抑制 剂的作用。

（6）呼觉加氧浮选的可能性及与体作用的机理和䙺律。

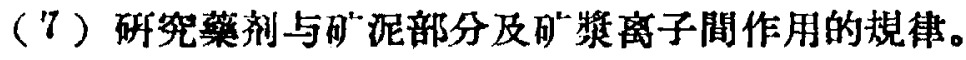

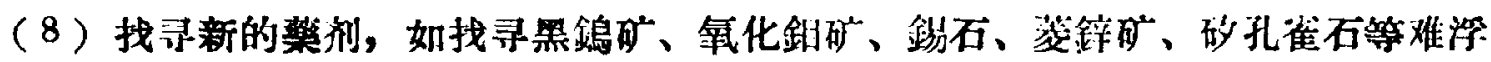

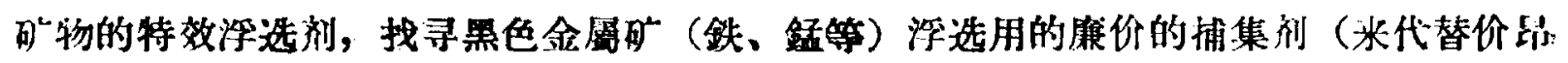
的油酸)，我寻矽酸監的石和锅酸監矿”石的有效抑制创等。 


\section{四 煤的浮选理論}

煤的浮选理論的研究不及矿石浮选理論那么多，这是因为大規模工業化的煤浮选厂， 在国际，上在 1941 年才开始初步發展，而到 1950 年以后, 才大大發起来的。在这以前， 有人以为煤的可浮性很好，煤的浮选是简而易行的事。但是当由于工業的需要（(1)來煤

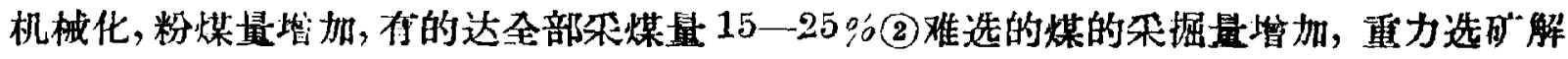

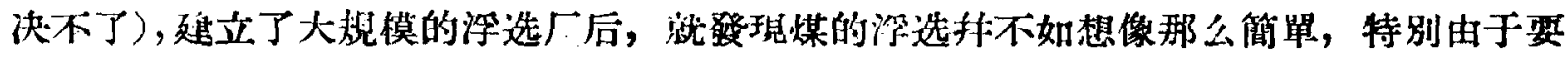
找寻不含酚的浮选剂（过去的研究工作都用含酚的藥剂，但此薬有素而且昆贵）。就侹問 題建显得复杂起来。

日前在煤浮选的生阫实踐中，已策取了一些基本上能使操作正規进行的办法。如找

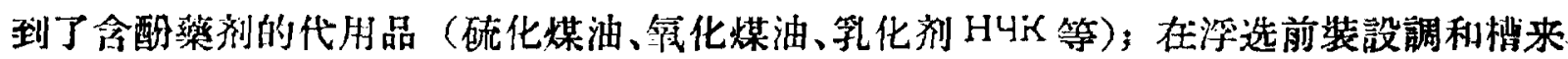

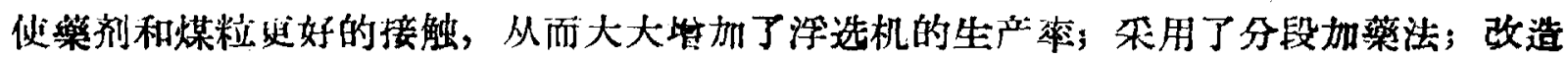
丁浮选机等。

但在理論上，目解的研究正在们各方面扩展着：首先，由于煤的組成的不沟匀性和

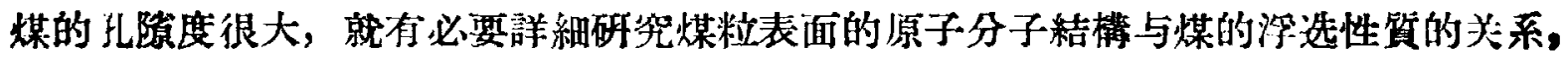
对于这方面，过去胁联許多煤岩学著（荕联燃料矿物研究所）已做了許多研究工作，可 以作为进一步呼究的基破。在苏联科学院矿業研究所，雅罗夫斯卡始 (M. Ф. Яновская) 和霍多特 B. B. Ходот 每研究了中等变算煤的孔陸度，测定了孔㗂的大小，分有及其他 婊面得的物理特性等。

其次，就是煤讪氧化与浮选的关系，藋对煤的作用过程是極其复杂的。开始时是吸 附过程，到最后是煤的全部氧化，这些过程使煤粒的表面大大地复杂化。苏联科学院矿 業研究所越雪罗夫斯基 (В. С. Веселовский) 制定了煤表面第化度的測定法, 进行了这 方面的研究，譬如說，研究証明重力选煤所留下的煤泥之所以不好哚，是由于其中积聚着

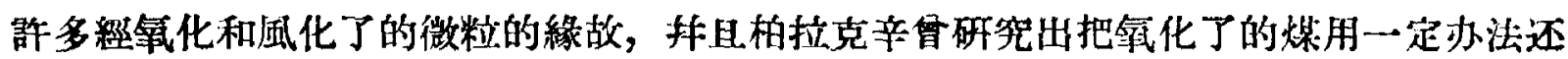
原之后，形以使它的叮浮性恢复。

日前用于选煤的浮选剂可分为两然：（1）非栖性結棈的，对水的作用弱，溶解度有

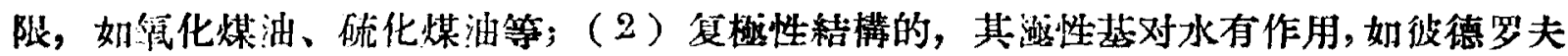
接触剂及醇类等。

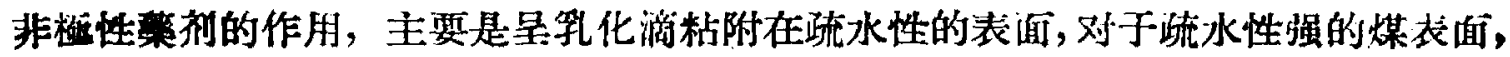

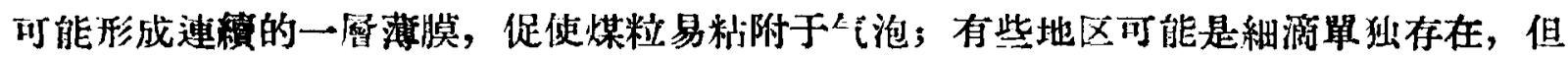

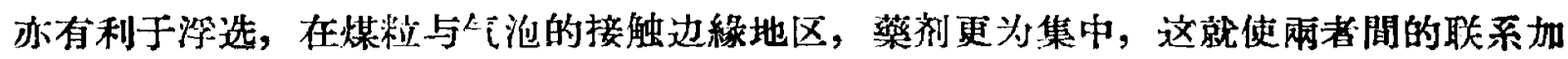
强，这就是粗粒煤可浴起的原因，此外，在液相中的笔化游，还会促成細粒的架凝，这 科觉凝在不过分的情况下，对浮选是有利的。

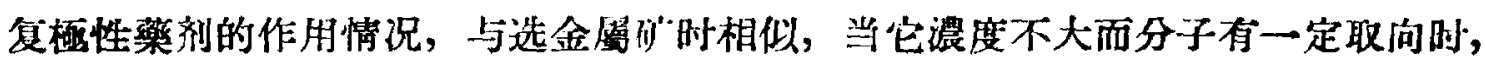
订使煤的表面造成疏水性而上浮，问时，这类菜剂有一定起泡性，造成很务微泡可在疏 水性的煤表面粘附，这些微泡可将細粒煤联䊅成“浮团”（аэро 㕮搌度太大时, 則在衣面品集合体存在, 就反过来变为亲水性。

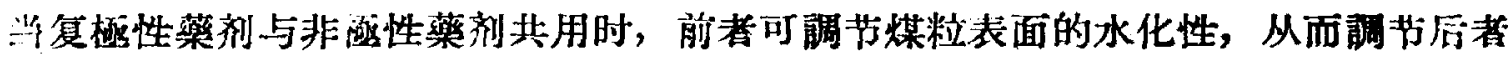




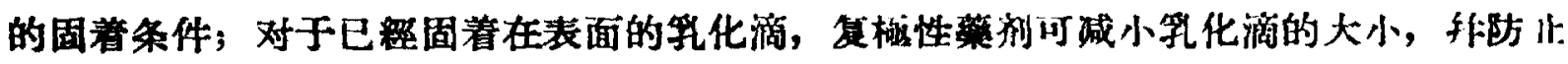
它的象玤。

許多研究工作部明，焢族的桱化合物的浮选活度，随其氢被 $\mathrm{OH}$ 或 $\mathrm{CO}$ 基的取代而

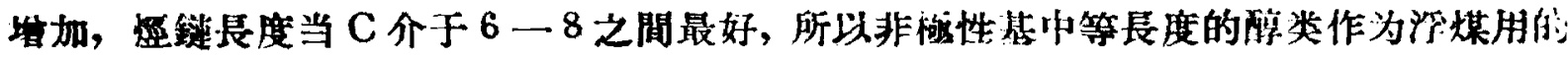

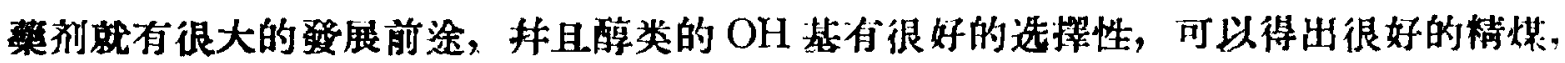

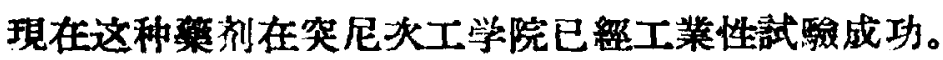

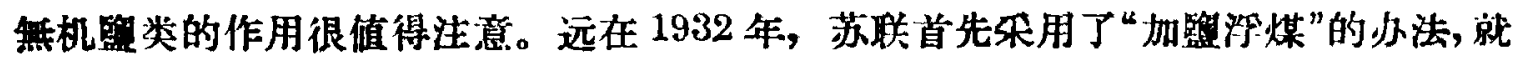

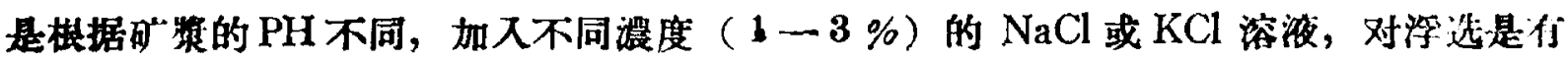
利的。为什么会这样呢? 过去有人以为留有利于起泡, 泡多了所以浮得好了, 伐这种不

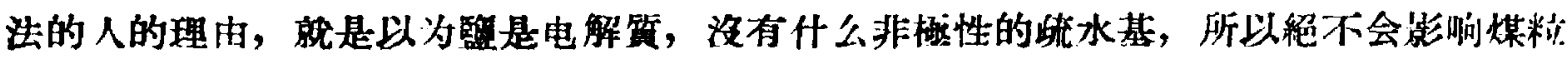
表面的水化性。

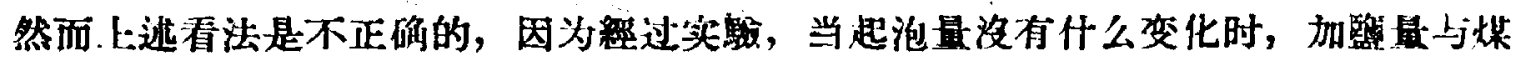

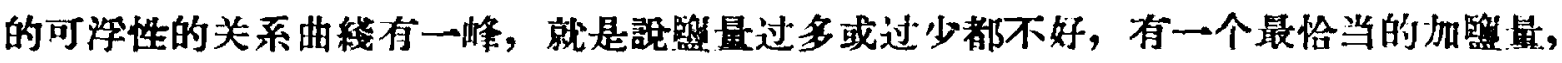

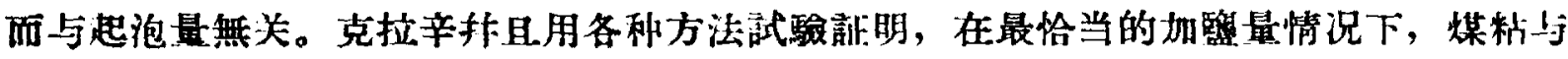
气泡的固着时間大大減少了（由 1.17 秒减至 0.032 秒，即减至 $1 / 37$ ），煤粒表面的水化脱 也不隐定了。

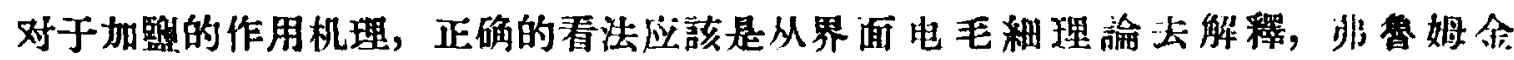
(A. H. Фрумкин) 院士对这理論有很詳細的研究，从他的覌点出發, 可以把煤不做是一

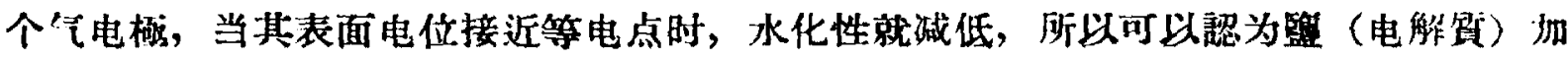

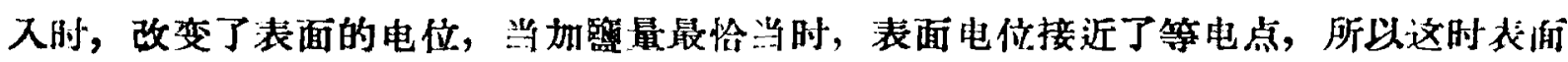
水化膜最不隐定。至于电解算如何起作用, 那最可能的情况是起离子吸附作用。

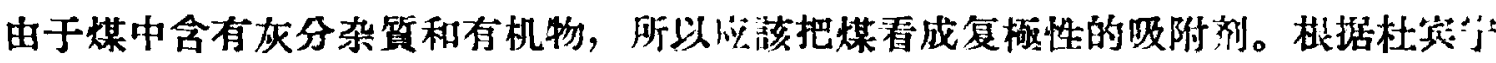
(M. М.Дубинин) 的砰究，电解質被煤吸附时，电解質离子能与溶液中的煤的杂質所形

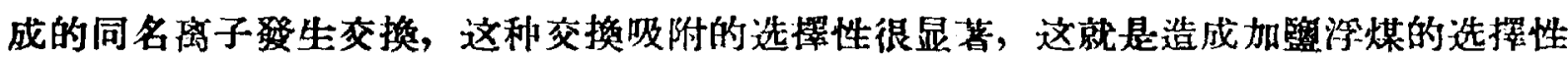

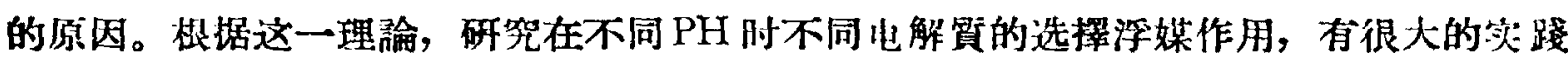

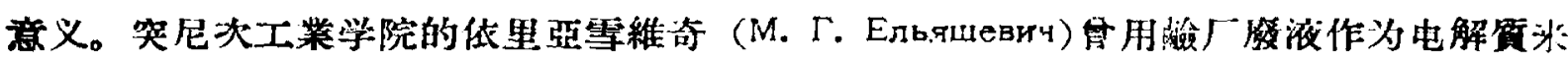
深煤，在实驗室和工業上都已得到很好的結果。

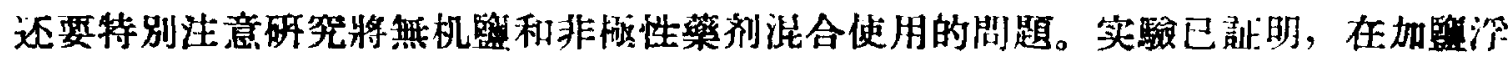
选时加入适量的（20-50 克/吨）非板性浮选剂，就使深选速度和精煤出最大大增加， 可以这样設想：無机監改变了煤表面的电性，使其水化膜不隐直，㘿加了表䤄的疏水性， 此时非梅性藥剂就能更坚固的固着。

很明显，上逃理諭的研究，将会使煤浮选工業开辟新的境界。

煤浮选时份应特別注意的是兩个因素: (1) 微䊉煤泥的作用; (2) 浮选机。

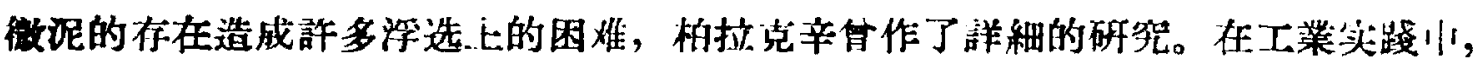

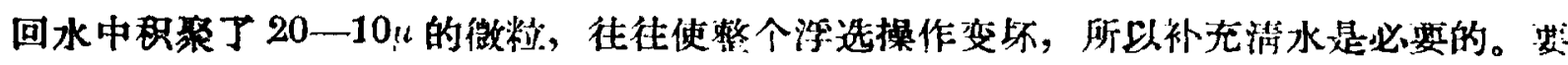

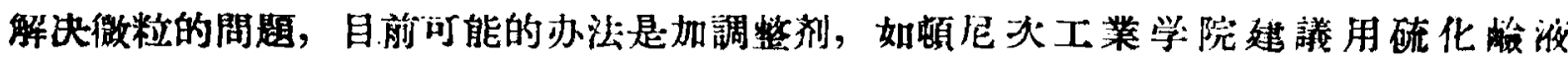
(Сульфитный щелок) 使徽粒腾溶, 但这洞題还校徹底解决。

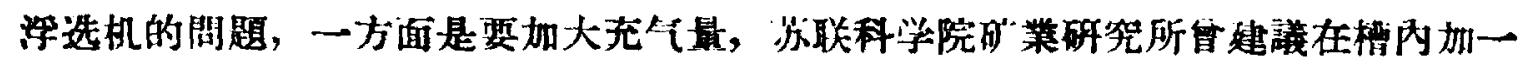




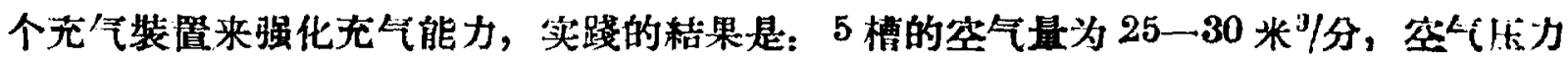

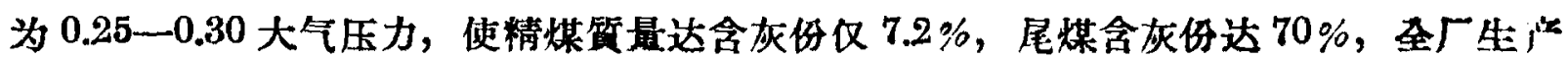
管提高了 $50 \%$ 。

另一方面由于精煤出量大, 要改装浮选机来适应这一特点。

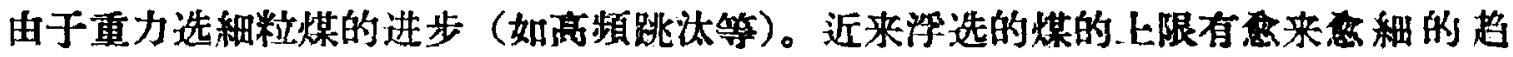
向, 从这覌点来看，有人稔为有必椠考虫用气升式浮选机。

媒浮选已發展成为極大的工業部門，从而許多新的理論問題涌現出来，須要加以解 决。目前有下面一些問題要进一步研究:

（1）研究煤粒的表面結構和組成及其浮选性犋; 研究按岩相成份进行分选的叮能 性。

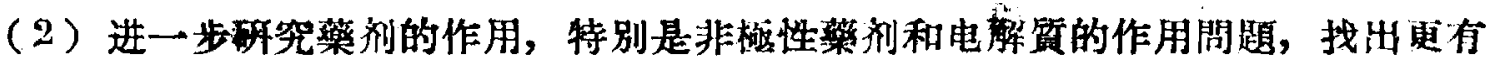
效而便管的浮选剂。

（3）研究除灰和除硫的办法，提高棈煤的粘焦性。

（4）研究新的浮选机，研究用气升机来清理回水的办法。

（5）研究合适的煤浮选操作条件（搌度、粒度、PH 樂方等)。

\section{总結}

浮选是一个过程，这一过程的每一阶段，都条涉到相界面所發生的物理的、化学的、 D及物理化学的現像。了解这些現像的本筫，找出其相互間的联系，發現支配这一过程 的規律, 从而使人們能掌捤这些規律来指导提调生产实踐, 这就是浮选理論研究的对像 和任务。

从全面来看，浮选理論可归納成几个主要問題:

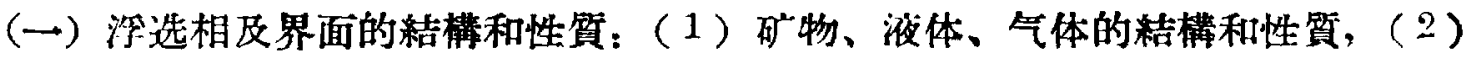
界面的粘棈和性質，(3) 毛細理論、电毛細理論、吸附理論等。

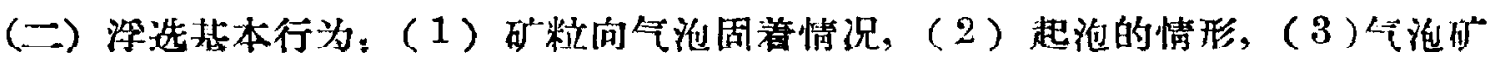
化的情况等。

（三）䒚剂的作用：（1）捕集剂的作用，（2）起泡剂的作用，(3)調整剂的作用 (包括气体作用等)。

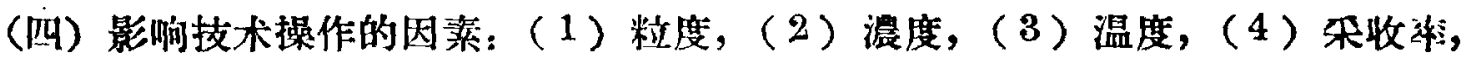

(5) 充气 (包括浮选机構造)，(6) 流程等等。

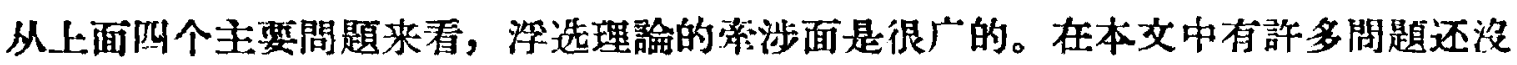
有詳細叙逊, 而有的重要問題（如浮选速度、矿化或然來, 界面双电尿, 起泡剂作用, 操作因莱等) 都没有詳細提及。

研觉二上列任何一个問題, 似应从兩方涌来探觉。

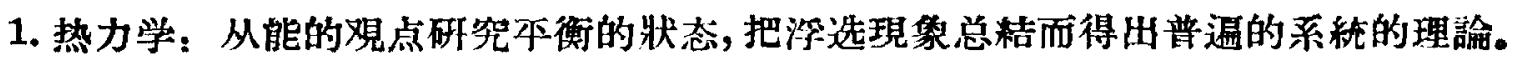

2. 动力学: 从分子䊅棈及运动出發, 研究过程各阶段的机理及本衡前后的情况。侹

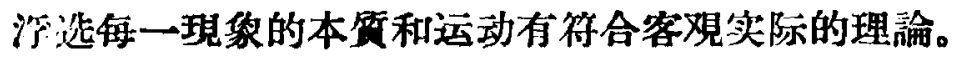


所以在討論每一問題时，应把这雨方面結合起来，就会对深选有全活的了解。

深选理踰可以鿁是近代科学中乎論比較多的問題之一。其所以如此，一方面是由于 沵洗过程的复杂性, 另一方面是由于浮选現等發生在微量的界面上, 这就使得研究方法 . ‥不一些困难, 从而使許多研究粘果先后矛盾, 或者很难做出結諭。这样就使得浮选理 論研究还不能强有力地領导浮选实踥, 而使浮选实踐还停留在“大最的試着做法”的阶段 ...

对于研究方法的研究, 是个頗为重要的問題, 目前用来研究浮选过程的方法是相当 多做:（1）通常的小型浮选机中进行的研究，(2) 接触角的測定，(3)不成泡浗的單

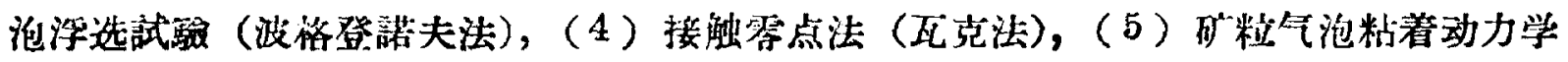
治（斯文一尼尔抙法），(6) 界面电毛細法（电动电位, 电永、超电位法)，(7) 快速

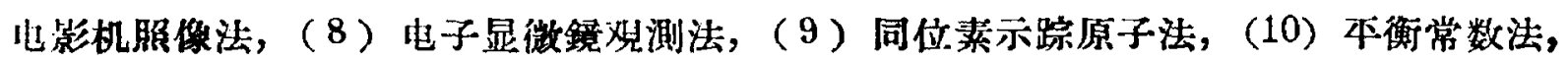
（11）放射照像法, (12) 美比紅外挠光新法, 以及 (13) 其他的化学分析法, 物理化学 分析法等。

在开展研究时, 必須注意采用先进的研觉方法, 当然, 对于不同的具体問題, 应采 用不同的合适的研究方法。

我园社会主义建設中，浮选工業將得到厂泛的發展，这就需要提傐深选的科学找术

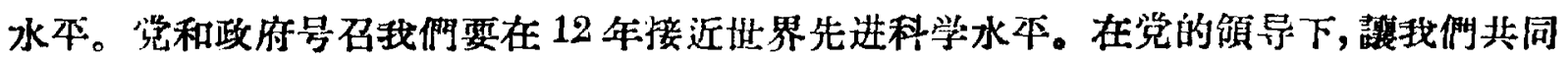
米努力吧!

\section{更正}

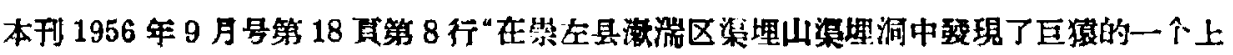

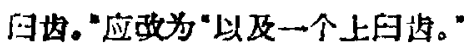

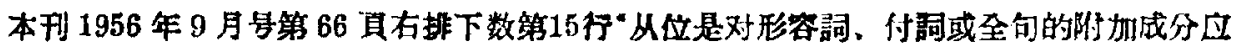
败为“从位詞是对动詞、形容詞、付菏、或全句的泭加成分。” 